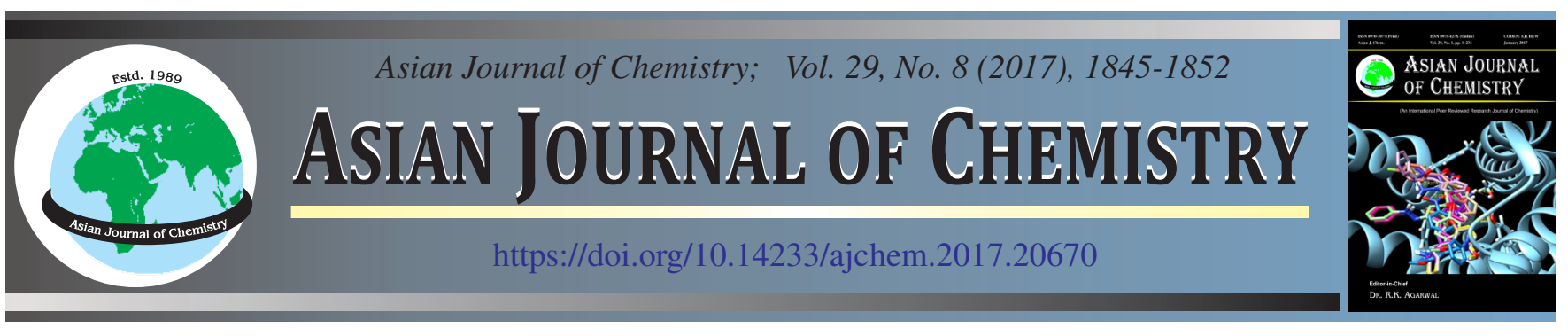

\title{
Validation of HPLC-MS Method in Positive Ion Mode for Estimation of Phenytoin in Human Plasma Using Phenytoin D10 as Internal Standard
}

\author{
Pallavi Alegete ${ }^{1,2}$, Prasad Kancherla ${ }^{3}$, Srinivas Keesari ${ }^{2}$, Siva Sanker Rao Yedlapalli ${ }^{2}$ and Sathyanarayana Boodida ${ }^{1, *}$
}

${ }^{1}$ Department of Chemistry, JNTUH College of Engineering, Nachupally, Jagtial, Karimnagar-505 501, India

${ }^{2}$ Piramal Clinical Research Laboratories, Ramanthapur, Hyderabad-500 013, India

${ }^{3}$ Institute of Science \& Technology, Jawaharlal Nehru Technological University Hyderabad, Kukatpally, Hyderabad-500 085, India

*Corresponding author: E-mail: bs14@jntuh.ac.in

Received: 25 March 2017;

Accepted: 26 April 2017;

Published online: 12 June 2017;

AJC-18452

\begin{abstract}
A high performance liquid chromatography mass spectrometric method for the estimation of phenytoin, in human plasma in positive ion mode was developed and validated using phenytoin D10 as internal standard (IS). Sample preparation was accomplished by solid-phase extraction technique. The eluted samples were chromatographed on Zorbax Eclipse XDB-Phenyl $4.6 \times 75$ mm, $3.5 \mu \mathrm{m}$ (Make: Agilent Technologies) column using a mobile phase consisting of HPLC grade acetonitrile: $0.1 \%$ formic acid (80:20 v/v). The method was validated over a concentration range of 101.253 to $10074.937 \mathrm{ng} \mathrm{mL}^{-1}$ for phenytoin. This validation report provides the results of selectivity, matrix effect, sensitivity determinations, precision and accuracy data, recovery and dilution integrity along with all pertinent documentation. An open label, balanced, randomized, two-treatment, two-period, two-sequence, cross-over, single oral dose bioequivalence study of phenytoin sodium $100 \mathrm{mg}$ capsules $(3 \times 100 \mathrm{mg}$, a total of $300 \mathrm{mg})$ of Green Evolution Laboratories, India comparing with phenytoin sodium flynn $100 \mathrm{mg}$ hard capsules $(3 \times 100 \mathrm{mg}$, a total of $300 \mathrm{mg}$ ) of Flynn Pharma Ltd, Alton House, Ireland in healthy, human adult subjects, under fasting conditions was conducted. The $90 \%$ confidence intervals were calculated for the $\mathrm{C}_{\max }, \mathrm{AUC}_{(0-\mathrm{t})}$ and $\mathrm{AUC}_{(0-\infty)}$, giving values between $96.26-110.38 \%$ demonstrating the bioequivalence of the two formulations.
\end{abstract}

Keywords: Phenytoin, Phenytoin-D10, Human plasma, LCMS/MS, Pharmacokinetic study.

\section{INTRODUCTION}

Epilepsy a most common central nervous system disorder may cause persistent deformity and decreasing the quality of life, affecting 50 million people worldwide [1]. Epilepsy is a chronic disorder that can influence human physiological, social and vocational functioning. The rate of mood disorders is higher in patients with epilepsy than in those with other chronic medical conditions, like diabetes or asthma [2-4]. Phenytoin is chemically known as 5,5-diphenyl-imidazoline-2,4-dione (Fig. 1) is one of the most widely used anticonvulsant drugs for the treatment of many epileptic-type seizures and is usually given orally in doses ranging from 200 to $600 \mathrm{mg}$ per day [57]. It is highly bound to the carrier protein human serum albumin and is mostly excreted in bile as inactive metabolites, which are then reabsorbed from the intestinal tract and excreted in the urine $[6,8]$. Poor water solubility, non-linear dosedependent pharmacokinetics and a narrow therapeutic window are the three pharmacologic characteristics associated with the risk of non-bioequivalence after the use phenytoin as generic drug [7-10]. The reported analytical methods used to determine phenytoin concentrations in biological samples includes biointeraction studies based on high performance affinity chromatography to investigate the binding of human serum albumin (HSA) to two major phenytoin metabolites [6] comparative bioavailability of a single oral $200 \mathrm{mg}$ dose of four brands of phenytoin sodium available in the Indian market [7], to determine the effect of gender and menstrual cycle on phenytoin bioavailability of $100 \mathrm{mg}$ extended phenytoin sodium capsules using HPLC assay [9] binding characteristics of phenytoin to serum proteins in the Japanese population [8] generic substitutions for antiepileptic drugs [10], determination of free and total levels of phenytoin in human plasma from patients with epilepsy by MEKC [11] (micellar electro kinetic chromatography), pharmacokinetic profile of a newly developed $300 \mathrm{mg}$ extended phenytoin sodium capsule (dilantin) formulation [12] double blind randomized study comparing brand name and generic phenytoin [13] comparative study of the bioavailability and dissolution of seven formulations of phenytoin [14], HPLC determination of lamotrigine in serum with phenytoin, carbamazepine and carbamazepine epoxide [15], simultaneous determination of phenytoin, carbamazepine 
and 10,11-carbamazepine epoxide in human plasma by highperformance liquid chromatography with ultraviolet detection [16], Simultaneous determination of lamotrigine, phenobarbitone, carbamazepine and phenytoin in human serum by highperformance liquid chromatography [17], quantification of carbamazepine, carbamazepine-10,11-epoxide, phenytoin and phenobarbital in plasma samples by stir bar-sorptive extraction and liquid chromatography [18], simultaneous determination of seven antiepileptic drugs (AEDs), including primidone, phenobarbital, phenytoin, carbamazepine with its two major metabolites carbamazepine-10,11-epoxide and carbamazepine10,11-(trans)-dihydrodiol in serum by high performance liquid chromatography (HPLC)-diode array detector (DAD) [19], HPLC assay method for the simultaneous determination of phenytoin and fosphenytoin in human plasma and plasma ultrafiltrate [20] and liquid chromatography-tandem mass spectrometry (LC-MS/MS) [21,22].

Reported literature approaches for this analysis include separation of free phenytoin by equilibrium dialysis and analysis by high performance liquid chromatography (HPLC) with UV detection [7], ultra filtration followed by HPLC with UV detection using liquid-liquid extraction with the long run time of $17 \mathrm{~min}$ [8] and automated sequential trace enrichment of dilalysate (ASTED) with HPLC with UV detection [10]. Some others RP-LC methods were reported for the determination of phenytoin in pharmacokinetics and bioequivalence studies, but without detailed description of the method and the validation parameters [7,12-14]. Also, LC methods for the simultaneous determination of phenytoin and other anticonvulsant drugs in biological matrix were developed using solid-phase extraction disk to separate the drugs [15], protein precipitation extraction $[16,17]$, stir adsorptive extraction [18] and solid-phase extraction using disposable cartridges with $1 \mathrm{~mL}$ sample volume capacity [19]. Moreover, the RP-LC method with UV detection was developed in the linear range from $0.4-400 \mu \mathrm{g} \mathrm{mL}^{-1}$ for the simultaneous determination of phenytoin and its prodrug fosphenytoin in human plasma and plasma ultrafiltrate [20], HPLC method for the determination of phenytoin in plasma or whole blood [21] LCMS assay for the determination of free levels of the highly protein bound drug phenytoin $(5,5-$ diphenylhydantoin) in human plasma by the drug/protein complex by ultrafiltration [21] and positive electrospray ionization [22-27], with liquid-liquid and protein precipitation extraction are reported, respectively. Determination of phenytoin in human plasma by gas chromatography is reported [28]. These approaches have associated with disadvantages including long sample preparation time and analysis time and high limits of quantitation and lack of complete validation procedures. To overcome the disadvantages of the above mentioned methods, we have studied a fully validated time high performance liquid chromatography mass spectrometric method for the estimation of phenytoin, in human plasma using Phenytoin D10 as an internal standard (IS). The usage of deuterated internal standard gives accurate results. The present method employs a simple solid-phase extraction (SPE) technique for sample preparation and phenytoin-d10 was used for the first time as an internal standard for the high performance liquid chromatography mass spectrometric method used for the estimation of phenytoin in human plasma in positive ion mode. The present method has a better runtime, recovery, precision and accuracy, matrix effect than that of the all previously reported methods. An open label, balanced, randomized, twotreatment, two-period, two-sequence, cross-over, single oral dose bioequivalence study of phenytoin sodium $100 \mathrm{mg}$ capsules $(3 \times 100 \mathrm{mg}$, a total of $300 \mathrm{mg})$ of Green Evolution Laboratories, India comparing with phenytoin sodium flynn $100 \mathrm{mg}$ hard capsules $(3 \times 100 \mathrm{mg}$, a total of $300 \mathrm{mg})$ of Flynn Pharma Ltd, Alton House, 4 Herbert Street, Dublin 2, Ireland in healthy, human adult subjects, under fasting conditions was conducted. The $90 \%$ confidence intervals were calculated for the $\mathrm{C}_{\max }, \mathrm{AUC}_{(0-\mathrm{t})}$ and $\mathrm{AUC}_{(0-\infty)}$, giving values between 96.26-110.38\% demonstrating the bioequivalence of the two formulations. The chemical structures of phenytoin and phenytoin-d10 (internal standard) are shown in Fig. 1.
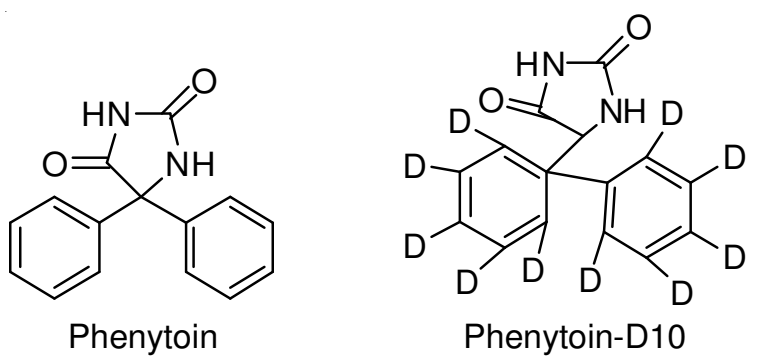

Fig. 1. Chemical structures of phenytoin and phenytoin-d10 (internal standard)

\section{EXPERIMENTAL}

Phenytoin $N, N$-dimethyl-2-(6-methyl-2- $p$-tolylimidazo[1,2-a]pyridin-3-yl)acetamide, hemitartrate) Purity: $100.0 \%$ (as is basis) obtained as a gifted sample from Splendid Labs Hyderabad, India. Phenytoin D10 purity: $99.16 \%$ (as is basis) obtained as a gifted sample from Splendid Labs, Hyderabad, India. HPLC Grade acetonitrile purchased from J.T. Baker (Philipsburg, USA). Analytical grade formic acid was purchased from Merck, Zorbax Eclipse XDB-Phenyl $4.6 \times 75$ mm $3.5 \mu \mathrm{m}$ (Make: Agilent Technologies) and HPLC grade water purchased from rankem. Water used in the entire analysis was prepared by a milli-Q water purification system (Millipore, Bangalore, India). The human K2EDTA control plasma was obtained from Vuppala Venkaiah memorial blood bank, (Hyderabad, India).

Chromatographic separation was carried out using a HPLC (LC 2010C, Shimadzu Corporation, Kyoto, Japan) equipped with a quaternary pump, a degasser, an autosampler, an injector with a $100 \mu \mathrm{L}$ loop, a column oven, a UV detector and a data system (Class VP version 6.12). The analytical column used was Zorbax Eclipse XDB-Phenyl $4.6 \times 75 \mathrm{~mm}$, $3.5 \mu \mathrm{m}$ for the desired separation. The mobile phase consisted of HPLC grade acetonitrile: $0.1 \%$ formic acid (80:20, v/v). The flow-rate of the mobile phase under isocratic condition was kept at $1.0 \mathrm{~mL} \mathrm{~min}{ }^{-1}$, injection volume was $15 \mu \mathrm{L}$. The sample cooler temperature was maintained at $15^{\circ} \mathrm{C}$ and the total run time was about $2.0 \mathrm{~min}$. Mass spectrometric detection was carried out using an API 3000 tandem mass spectrometer (Applied Biosystems/MDS SCIEX, Toronto, ON, Canada) 
equipped with an electrospray ionization (ESI) source. The mass spectrometer was operated in positive ion mode and the tandem mass spectrometry conditions for phenytoin and the internal standard (IS, Phenytoin-D10) were optimized by carrying out full scans in positive ion detection mode.

\section{Preparation of stock and working solutions}

Phenytoin stock solution: $5.0124 \mathrm{mg}$ of phenytoin working standard was transferred to a $5 \mathrm{~mL}$ clean glass volumetric flask, dissolved in HPLC grade methanol and made up to the volume produce a solution of $1 \mathrm{mg} \mathrm{mL}^{-1}$. Corrected the above concentration of phenytoin solution accounting for its potency and the actual amount weighed. The stock solution was stored in refrigerator at $2-8{ }^{\circ} \mathrm{C}$ and used for maximum of $166 \mathrm{~h}$. The stock solutions were diluted to suitable concentrations using a mixture of acetonitrile and HPLC grade water in the ratio of $(60: 40 \mathrm{v} / \mathrm{v})$ for spiking into plasma to obtain calibration curve (CC) standards, quality control (QC) samples and DIQC samples. For the preparation of calibration curve standards and quality control samples separate stock solutions were used. All other final dilutions (system suitability dilutions, aqueous mixture, etc.) were prepared in mobile phase.

Phenytoin D10 stock solution (internal standard): Weighed about $5.1642 \mathrm{mg}$ of phenytoin D10 transferred to a $5 \mathrm{~mL}$ volumetric flask, dissolved in HPLC grade methanol and made up the volume with the same to produce a solution of $1 \mathrm{mg} \mathrm{mL}^{-1}$. Corrected the above concentration of phenytoin D10 accounting for its molecular weight, potency and the actual amount weighed. The stock solution was stored in refrigerator at $2-8{ }^{\circ} \mathrm{C}$ and used for maximum of $166 \mathrm{~h}$.

Calibration curve standards and quality control samples: Calibration curve standard consisting of a set of ten non-zero concentrations ranging from 101.253 to 10074.937 $\mathrm{ng} \mathrm{mL} \mathrm{m}^{-1}$ of phenytoin were prepared. Prepared quality control samples consisted of concentrations of $101.437 \mathrm{ng} \mathrm{mL}^{-1}$ (LLOQ QC), $301.897 \mathrm{ng} \mathrm{mL}^{-1}$ (LQC), $1509.484 \mathrm{ng} \mathrm{mL}^{-1}$ (MQC1), $5031.615 \mathrm{ng} \mathrm{mL}^{-1}$ (MQC2) and $7549.310 \mathrm{ng} \mathrm{mL}^{-1}$ (HQC) for phenytoin. These samples were stored at $-70{ }^{\circ} \mathrm{C}$ until use. Twelve sets of LQC and HQC were stored at $-20^{\circ} \mathrm{C}$ deep freezer to check $-20^{\circ} \mathrm{C}$ stability. Twelve sets of quality control samples for dilution integrity were prepared by spiking about 1.60 times (16139.903 $\left.\mathrm{ng} \mathrm{mL}^{-1}\right)$ and another twelve sets by spiking about 3.2 times $\left(32279.807 \mathrm{ng} \mathrm{mL}^{-1}\right)$ highest standard concentration of phenytoin. From these, six sets each of two times dilution and four-time dilution was performed.

Sample preparation: The samples were thawed at room temperature and vortexed to ensure complete mixing of the contents. $250 \mu \mathrm{L}$ of the plasma sample was pipetted in toc pre-labelled RIA vial tubes. $25 \mu \mathrm{L}$ of internal standard dilution (phenytoin D10 at a concentration of $50 \mathrm{ng} \mathrm{mL}^{-1}$ ) was added to it and vortexed, except in blank plasma samples where $25 \mu \mathrm{L}$ diluent was added and vortexed. Then $250 \mu \mathrm{L}$ of $0.1 \%$ formic acid was added and vortexed. The sample mixture was loaded onto Strata-X $33 \mu \mathrm{m}$ polymeric sorbent cartridge $\left(30 \mathrm{mg} \mathrm{mL}^{-1}\right)$ that were pre-conditioned with $1.0 \mathrm{~mL}$ of HPLC grade methanol followed by $1 \mathrm{~mL}$ Milli Q water (new cartridge for each sample). After applying the maximum pressure the extraction cartridge was washed with $2 \mathrm{~mL}$ of Milli Q/HPLC grade water $(1 \mathrm{~mL}$ of each time). Then the samples were eluted with $2 \mathrm{~mL}$ of eluent, tert-butyl methyl ether and evaporated up to dryness at $45{ }^{\circ} \mathrm{C}$ under gentle stream of nitrogen. The dried extract sample was reconstituted with $500 \mu \mathrm{L}$ of the mobile phase and transferred into auto sampler loading vials and loaded in the auto sampler and injected.

Method validation: Thorough and complete method validation of phenytoin in human plasma was carried out for selectivity, sensitivity, linearity, precision and accuracy, recovery, matrix effect, dilution integrity and stability according to US Food and Drug Administration (FDA, 2001 and European Medicines Agency (EMEA) 2009 [29,30].

Selectivity: Selectivity is the ability of an analytical method to differentiate and quantify the analyte in the presence of other components in the sample. The selectivity of the method was evaluated by processing six different lots of blank plasma sample. These samples were spiked with LLOQ concentration along with internal standard to confirm the lack of interference at their retention time and absence of lot to lot variation.

Linearity: A regression equation with a weighting factor of $1 /$ (concentration ratio $)^{2}$ of drug to internal standard concentration was judged to produce the best fit for the concentrationdetector response relationship for phenytoin in human plasma. The representative calibration curve for regression analysis and correlation coefficient $\left(r^{2}\right)$ was greater than 0.99 in the concentration range of 101.253 to $10074.937 \mathrm{ng} \mathrm{mL}^{-1}$ for phenytoin.

Precision and accuracy: The precision of the assay was measured by the percent coefficient of variation over the concentrations of LLOQ, QC, LQC, MQC1, MQC2 and HQC samples during the course of validation. The accuracy of the assay was defined as the absolute value of the ratio of the calculated mean values of the LLOQ, low, middle and high quality control samples to their respective nominal values, expressed in percentage.

Absolute matrix effect: The matrix effect was assessed as recommended by Matuszewski [31] in 8 batches. The assessment of relative matrix effect was based on direct comparison of the MS/MS responses (peak areas) of the analytes spiked into extracts originating from different lots of plasma. The variability in these responses, expressed as $\mathrm{CV} \%$, was considered as the measure of relative matrix effect (Table-1).

Stability studies and dilution integrity: Stability experiments were performed to evaluate the analyte stability in stocks solutions and in plasma samples under different conditions, which may occur during sample analysis. Stock solution stability was performed by comparing area response of stability samples of analytes and the internal standard with the area response of sample prepared from fresh stock solutions. Benchtop stability, extracted sample stability (wet extract stability), freeze-thaw stability, dry extract stability and long-term stability were performed at LQC and HQC level using six replicates at each level. The dilution integrity experiment was intended to validate the dilution test to be carried out on higher analyte concentrations (above HQC), which may be encountered during real subject samples analysis.

Method development: Various mobile phase compositions of acetonitrile/methanol with acidic modifiers like formic 
TABLE-1

MATRIX EFFECT OF PHENYTOIN IN HUMAN PLASMA

\begin{tabular}{|c|c|c|c|c|c|c|}
\hline \multirow[b]{2}{*}{ Plasma lot } & \multicolumn{3}{|c|}{ LQC301.897 } & \multicolumn{3}{|c|}{ HQC 7549.310} \\
\hline & $\begin{array}{c}\text { Concentration } \\
\text { found }\end{array}$ & Accuracy (\%) & $\begin{array}{l}\text { Internal standard - } \\
\text { Normalized MF }\end{array}$ & $\begin{array}{c}\text { Concentration } \\
\text { found }\end{array}$ & Accuracy (\%) & $\begin{array}{c}\text { Internal standard - } \\
\text { Normalized MF }\end{array}$ \\
\hline 1 & 304.415 & 100.83 & 1.00 & 7553.154 & 100.05 & 1.01 \\
\hline 2 & 312.007 & 103.35 & 0.97 & 7565.46 & 100.21 & 1.01 \\
\hline 3 & 314.494 & 104.17 & 0.95 & 7597.322 & 100.64 & 1.00 \\
\hline 4 & 320.819 & 106.27 & 1.02 & 7792.341 & 103.22 & 1.01 \\
\hline 5 & 317.578 & 105.19 & 1.01 & 7617.831 & 100.91 & 1.02 \\
\hline 6 & 314.397 & 104.14 & 0.99 & 7513.575 & 99.53 & 1.00 \\
\hline
\end{tabular}

acid, ammonium acetate and ammonium formate were tested in different volume ratios. Moreover various chromatographic columns like $\mathrm{C} 8$ and $\mathrm{C} 18$ of different make (Kromasil 100$5 \mathrm{C}_{18}, 100 \times 4.6,5 \mu \mathrm{m}$; Alltima HP C $18,50 \times 4.6,3 \mu \mathrm{m}$; Zorbax $\mathrm{SB} \mathrm{C}_{18}, 50 \times 4.6,5 \mu \mathrm{m}$; Zorbax XDB-phenyl 75 × 4.6, $3.5 \mu \mathrm{m}$; Ace $3 \mathrm{C}_{18}, 150 \times 4.6,3 \mu \mathrm{m}$; Hypurity advance $75 \times 4.6,5 \mu \mathrm{m}$; Discovery HS $\mathrm{C}_{18} 50 \mathrm{~mm} \times 4.6 \mathrm{~mm}, 5 \mu \mathrm{m}$ ) were tested to achieve satisfactory retention time with a shorter run time, desirable separation from endogenous components, symmetric peak shape and adequate response for the analyte. The response obtained with acetonitrile and $0.1 \%$ formic acid as the mobile phase was satisfactory. The eluted samples were chromatographed on zorbax Eclipse XDB-Phenyl $4.6 \times 75 \mathrm{~mm}, 3.5 \mu \mathrm{m}$ (Make: Agilent Technologies) column using a mobile phase consisting of HPLC grade acetonitrile: $0.1 \%$ formic acid $(80: 20 \mathrm{v} / \mathrm{v})$. The retention times of analyte and internal standard obtained with the above optimized chromatographic conditions were low enough $(0.87$ and $0.86 \mathrm{~min})$ allowing a short run time of $2 \mathrm{~min}$.

\section{RESULTS AND DISCUSSION}

Mass spectrometry: Phenytoin and internal standard were tuned in both positive and negative ionization modes initially, we opted ESI as the ionization source in the positive ionization mode for the method development as the response obtained in positive mode was much higher than in negative mode. The protonated form of analyte and internal standard, $[\mathrm{M}+\mathrm{H}]^{+}$ion, was the precursor ion in the Q1 spectrum and was used as the precursor ion to obtain Q3 product ion spectra. The most sensitive mass transition was observed from $\mathrm{m} / \mathrm{z} 253.20$ (parent) and $\mathrm{m} / \mathrm{z} 182.10$ (product) for phenytoin and from $\mathrm{m} / \mathrm{z}$ 263.20 (parent) and $m / z 192.20$ (product) for the internal standard (Fig. 2). The most intense and consistent product ion in Q3 MS spectra of the analyte and the internal standard was obtained by optimizing the collision energy and collision cell exit potential. The source parameters like nebulizer gas (GS1), auxiliary gas (GS2), collision gas, temperature and ion spray voltage were optimized to obtain adequate and reproducible response for the analyte. The dwell time for each transition was set at $200 \mathrm{~ms}$.

Bioequivalence study: The study was an open, randomized, two-treatment, two-period, two-sequence, cross-over, single oral dose bioequivalence study with a two-week washout interval between the doses. After check-in, subjects received a standard meal (day 0), at dinner consisting of 1000-1200 k.cal after which they will be required to fast overnight (for at least $10 \mathrm{~h}$ ) and a standard meals comprising of 2200-2400

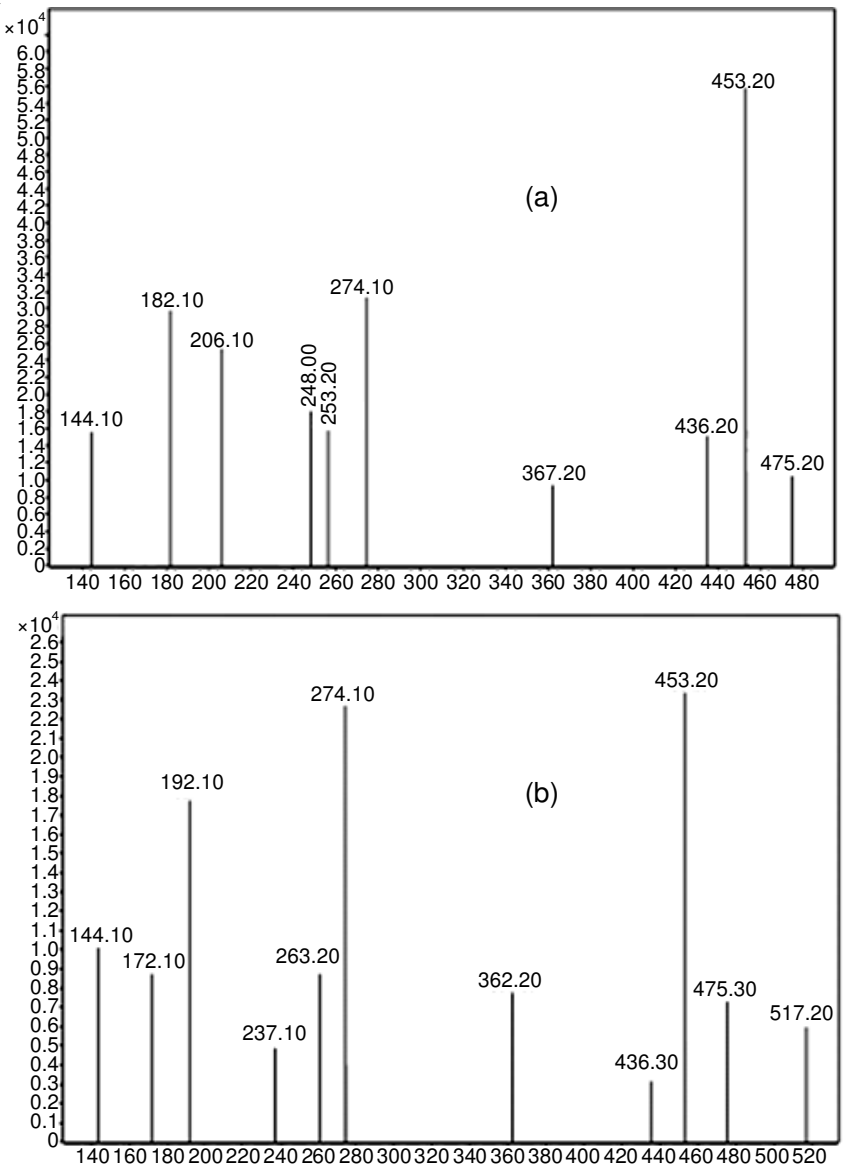

Fig. 2. Product ion mass spectra of (a) phenytoin and (b) phenytoin-d10

k.cal will be provided at 4,8 and 13 h post-dose (i.e. lunch, snacks, dinner respectively) on day 1 , a standard meal comprising of approximately $2400-2800 \mathrm{k}$.cal will be provided at $25,29,33$ and $37 \mathrm{~h}$ post dose (i.e. breakfast, lunch, snacks and dinner respectively) on day 2 , a standard meal comprising of approximately $2400-2800 \mathrm{k} . c a l$ will be provided at 49, 53, 57 and $61 \mathrm{~h}$ post dose (i.e. breakfast, lunch, snacks and dinner respectively) on day 3 , a standard meal comprising of approximately $2400-2800 \mathrm{k} . c a l$ will be provided at $73,77,81$ and $85 \mathrm{~h}$ post dose (i.e. breakfast, lunch, snacks and dinner respectively). Drinking water will be restricted for $1 \mathrm{~h}$ before and $1 \mathrm{~h}$ after investigational product administration except 240 $\pm 2 \mathrm{~mL}$ of water given for investigational product administration. Sixteen male healthy volunteers aged between 18 and 45 years and within $15 \%$ of the ideal body weight were selected by clinical evaluation and laboratory tests [29,30]. The clinical protocol was approved by the local ethic committee and the 
volunteers given written informed agreement to participate in the study. Twenty five blood samples $(1 \times 4 \mathrm{~mL})$ will be collected in pre-labelled K2 EDTA vacutainers. Single venous blood sample will be withdrawn at pre-dose $(0.00)$ and 0.50 , $1.00,2.00,3.00,4.00,5.00,6.00,7.00,8.00,9.00,10.00,11.00$, $12.00,13.00,14.00,16.00,20.00,24.00,36.00,48.00,72.00$, $96.00,120.00$ and $144.00 \mathrm{~h}$ post-dose. The samples were immediately centrifuged (at $2500 \mathrm{rpm}$ for $5 \mathrm{~min}$ at $4{ }^{\circ} \mathrm{C}$ ), the plasma separated and kept frozen at $-80{ }^{\circ} \mathrm{C}$ into labeled cryogenic tubes until assayed. A single oral dose of (three capsules) of phenytoin sodium $100 \mathrm{mg}$ capsules $(3 \times 100 \mathrm{mg}$, a total of $300 \mathrm{mg}$ ) of test product $(\mathrm{T})$ or phenytoin sodium flynn 100 $\mathrm{mg}$ hard capsules $(3 \times 100 \mathrm{mg}$, a total of $300 \mathrm{mg})$ of reference product $(\mathrm{R})$ was administered as per the randomization schedule under fasting conditions. Each subject received the alternate 'treatment' in the subsequent period, in such a way that each subject will receive both the 'treatments' by the end of the study.

Selectivity: No interference was observed at retention time of phenytoin D10 when ULOQ concentration of phenytoin injected. Similarly, No significant interference was observed at retention time of phenytoin when working concentration of phenytoin D10 injected (Table-2).

The selectivity of the method was evaluated by analyzing a blank human plasma extract (Fig. 3A) and an extract spiked

\begin{tabular}{|c|c|c|c|c|}
\hline \multicolumn{5}{|c|}{$\begin{array}{c}\text { TABLE-2 } \\
\text { INTER-DAY AND INTRA-DAY PRECISION AND } \\
\text { ACCURACY FOR THE DETERMINATION OF } \\
\text { PHENYTOIN IN HUMAN PLASMA }\end{array}$} \\
\hline $\begin{array}{l}\text { Quality } \\
\text { control }\end{array}$ & Run & $\begin{array}{l}\text { Concentration found } \\
\left(\text { Mean } \pm \text { SD ng mL } \mathrm{mL}^{-1}\right)\end{array}$ & $\begin{array}{l}\text { Precision } \\
(\%)\end{array}$ & $\begin{array}{c}\text { Accuracy } \\
(\%)\end{array}$ \\
\hline \multicolumn{5}{|c|}{ Within batch Precision (five replicates at each concentration) } \\
\hline \multirow{5}{*}{ LLOQ } & 1 & $100.9403 \pm 4.40178$ & 4.36 & 99.51 \\
\hline & 2 & $97.8483 \pm 7.12242$ & 7.28 & 96.46 \\
\hline & 3 & $100.0903 \pm 5.44887$ & 5.44 & 98.67 \\
\hline & 4 & $102.4443 \pm 5.83219$ & 5.69 & 100.99 \\
\hline & 5 & $98.3947 \pm 3.05980$ & 3.11 & 97.00 \\
\hline \multirow{5}{*}{ LQC } & 1 & $315.5153 \pm 5.12792$ & 1.63 & 104.51 \\
\hline & 2 & $314.6637 \pm 5.22432$ & 1.66 & 104.23 \\
\hline & 3 & $320.8195 \pm 8.54987$ & 2.67 & 106.27 \\
\hline & 4 & $307.1255 \pm 7.76445$ & 2.53 & 101.73 \\
\hline & 5 & $313.9517 \pm 5.57732$ & 1.78 & 103.99 \\
\hline \multirow{5}{*}{ MQC1 } & 1 & $1563.0060 \pm 27.72692$ & 1.77 & 103.55 \\
\hline & 2 & $1566.7513 \pm 19.12779$ & 1.22 & 103.79 \\
\hline & 3 & $1561.1212 \pm 24.48680$ & 1.57 & 103.42 \\
\hline & 4 & $1446.0695 \pm 11.25903$ & 0.78 & 95.80 \\
\hline & 5 & $1486.2277 \pm 32.24735$ & 2.17 & 98.46 \\
\hline \multirow{5}{*}{ MQC2 } & 1 & $4951.7305 \pm 77.94930$ & 1.57 & 98.41 \\
\hline & 2 & $4959.5072 \pm 113.23944$ & 2.28 & 98.57 \\
\hline & 3 & $4955.8138 \pm 120.40596$ & 2.43 & 98.49 \\
\hline & 4 & $4880.3007 \pm 102.22584$ & 2.09 & 96.99 \\
\hline & 5 & $4815.3207 \pm 36.89935$ & 0.77 & 95.70 \\
\hline \multirow{5}{*}{ HQC } & 1 & $7498.0583 \pm 178.35924$ & 2.38 & 99.32 \\
\hline & 2 & $7566.7212 \pm 158.63736$ & 2.10 & 100.23 \\
\hline & 3 & $7426.9042 \pm 179.02481$ & 2.41 & 98.38 \\
\hline & 4 & $7525.2123 \pm 144.14233$ & 1.92 & 99.68 \\
\hline & 5 & $7606.6138 \pm 97.89235$ & 1.29 & 100.76 \\
\hline \multicolumn{5}{|c|}{ Between batch precision (30 replicates at each concentration) } \\
\hline LLC & & $99.9436 \pm 5.25293$ & 5.26 & 98.53 \\
\hline LQ & & $314.4151 \pm 7.57551$ & 2.41 & 104.15 \\
\hline $\mathrm{MQ}$ & & $1524.6351 \pm 55.04064$ & 3.61 & 101.00 \\
\hline $\mathrm{MQ}$ & & $4912.5346 \pm 105.48331$ & 2.15 & 97.63 \\
\hline $\mathrm{HQ}$ & & $7524.7020 \pm 156.40757$ & 2.08 & 99.67 \\
\hline
\end{tabular}

only with the IS (Fig. 3B). As shown in Fig. 3A, no significant direct interference in the blank plasma samples was observed from external substances in drug-free human plasma at the retention time of analyte and internal standard. Similarly, Fig. $3 \mathrm{~B}$ shows the absence of direct interference from the internal standard to the MRM channel of analyte. Fig. 3C depicted a representative ion-chromatogram for the LLOQ QC sample (101.437 ng mL $\mathrm{m}^{-1}$ ). Typical MRM chromatograms of phenytoin and internal standard in human blank plasma (A), and human plasma spiked with internal standard (B), and a LLOQ QC sample along with internal standard (C) are shown in Fig. 3.

Linearity: The representative calibration curve for regression analysis and correlation coefficient $\left(\mathrm{r}^{2}\right)$ was greater than 0.99 in the concentration range of 101.253 to $10074.937 \mathrm{ng}$ $\mathrm{mL}^{-1}$ for phenytoin.

Precision and accuracy: Within-batch precision for LLOQ QC, LQC, MQC1, MQC2 and HQC ranged from 3.11-7.28, $1.63-2.67,0.78-2.17,0.77-2.43$ and $1.29-2.41 \%$, respectively.

Between batch precision for LLOQ QC, LQC, MQC1, MQC2 and HQC was 5.26, 2.41, 3.61, 2.15 and $2.08 \%$, respectively.

Stability studies and dilution integrity: Using the mean of six replicates $(n=6)$, freeze thaw, wet extract, autosampler, bench top and short-term stability was assessed for stock solutions of phenytoin and internal standard. The per cent nominal ranged from 106.19 to $107.11 \%$ and the precision ranged 1.05 to $1.46 \%$ for four freeze thaw cycles. The results of wet extract stability studies demonstrate that the processed samples were stable for $29 \mathrm{~h} 39 \mathrm{~min}$ at $2-8{ }^{\circ} \mathrm{C}$. The per cent nominal at $29 \mathrm{~h} 39 \mathrm{~min}$ ranged from 105.78 to $107.92 \%$ and precision ranged from 1.16 to $2.00 \%$. The results of autosampler studies demonstrate that the processed samples were stable for $33 \mathrm{~h} 35 \mathrm{~min}$. The percent nominal at $33 \mathrm{~h} 35 \mathrm{~min}$ ranged from 108.20 to $109.07 \%$ and precision ranged from 1.36 to $1.99 \%$. The results of Bench top stability study shown that the percent nominal ranged from 100.79 to $103.86 \%$ and the precision ranged from 1.48 to $2.48 \%$ and The percent of short-term stability ranged from 97.55 to $98.12 \%$ and the precision ranged from 0.70 to $1.83 \%$ (Table-3).

Dilution integrity: Twelve sets of dilution integrity samples were prepared by spiking 1.60 time's of highest standard concentration ( $\left.321.033 \mathrm{ng} \mathrm{mL}^{-1}\right)$. Six sets of dilution integrity samples were processed by diluting them twice and another six sets were processed by diluting them four times. These samples were analyzed along with a processed calibration curve standards (undiluted) of concentration range equivalent to that used for the calculation of precision and accuracy batch3. The quality control sample concentrations were calculated using appropriate dilution factor. Phenytoin results demonstrate acceptable dilution integrity for two and four time's dilution. Phenytoin precision and accuracy, for a dilution factor of 2 was 0.70 and $101.88 \%$, respectively. Similarly, phenytoin precision and accuracy, for a dilution factor of 4 was 0.81 and $104.28 \%$, respectively.

Pharmacokinetics and statistical analysis: The pharmacokinetic parameters of phenytoin, namely the maximum plasma concentration $\mathrm{C}_{\max }$ and time point of maximum plasma concentration $\mathrm{T}_{\max }$ were obtained directly from the measured 
A Blank-Phenytoin (Double Blank) 253.2/182.1 amu

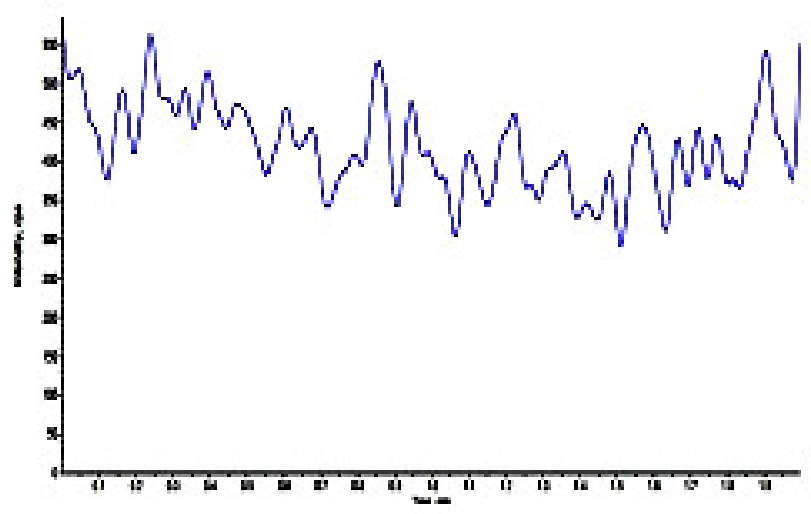

B Blank+1S-Phernytoin (Blank) 253.2/1821 amu

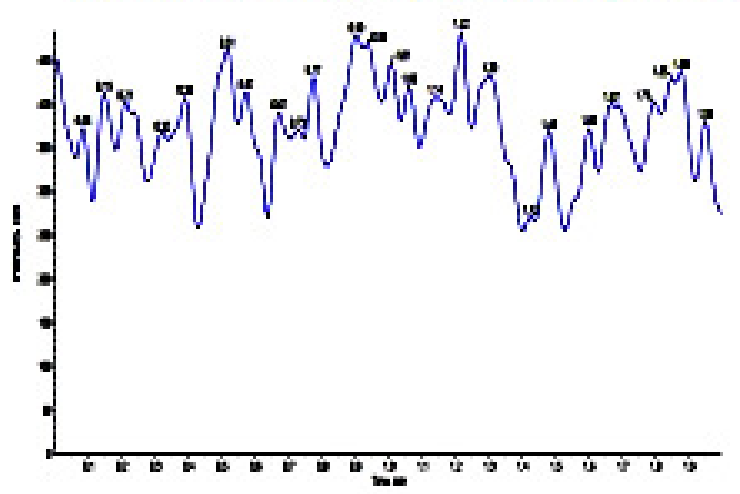

C LLOQQC-01-Phenytoin (QC) 253.2/1821 amu

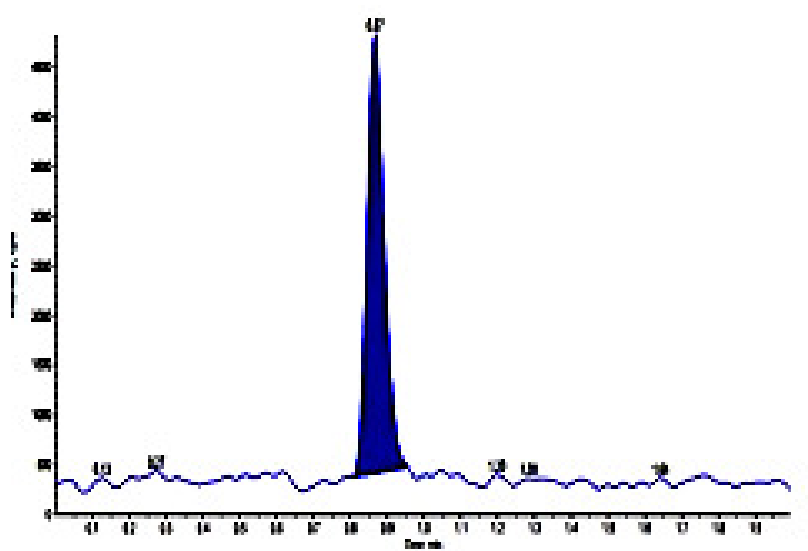

Blank-Phenytoin D-10 (IS) (Double

Blank) 263.2/192.2 amu

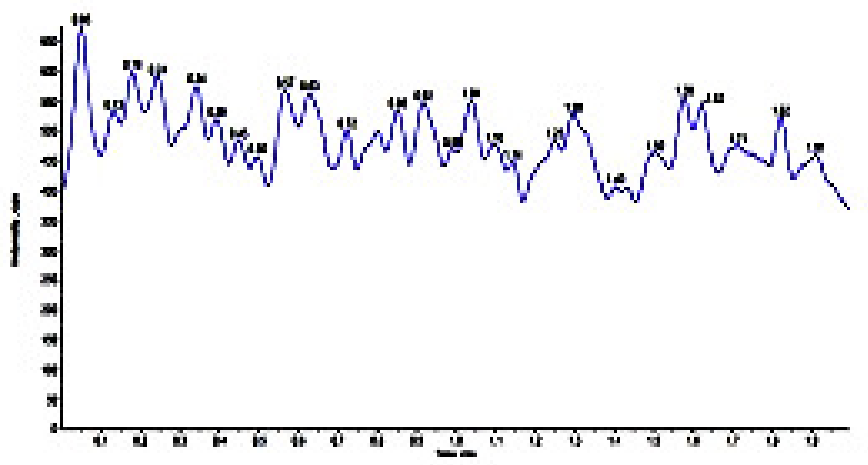

Blank+1S Phenytoin D-1O(IS) (Blank)

263.2/192.2 amu

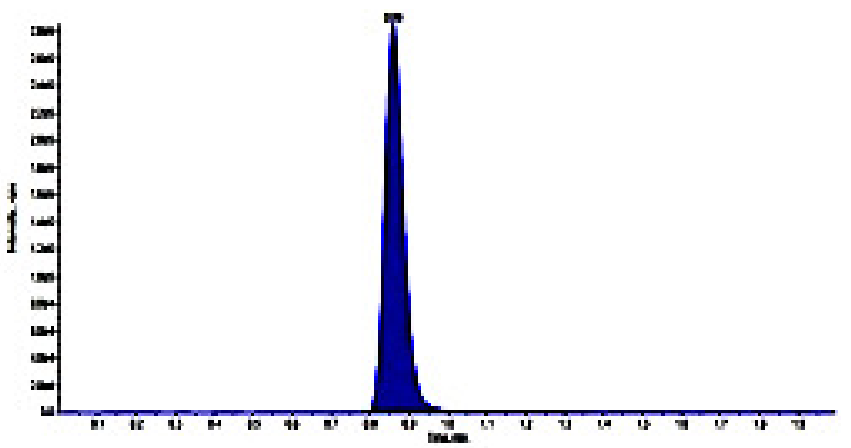

ШOQ QC-01 Phenytoin D-10 (IS) (QC)

263.2/192.2 amu

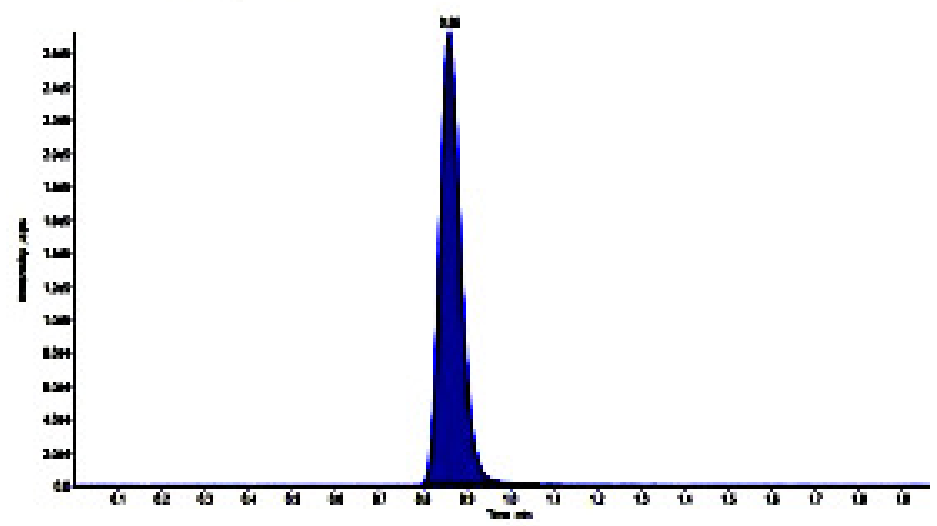

Fig. 3. Typical MRM chromatograms of phenytoin and internal standard in human blank plasma (A), human plasma spiked with internal standard (B), a LLOQ QC sample along with internal standard (C)

data. The area under the phenytoin plasma concentration time curve $\mathrm{AUC}_{(0-\mathrm{t})}$ was computed using the linear trapezoidal rule, whereas, the area under the concentration plasma time curve from time 0 to the infinity $\mathrm{AUC}_{(0-\infty)}$ was calculated as the sum of $\mathrm{AUC}_{(0-\mathrm{t})}$ and $\mathrm{C}_{\mathrm{t}} / \mathrm{k}_{\mathrm{e}}$, where $\mathrm{t}$ was the time of the last measurable concentration $\left(\mathrm{C}_{\mathrm{t}}\right)$ and $\mathrm{k}_{\mathrm{e}}$ was the elimination rate constant. Fig. 4 depicts the mean plasma concentration $v s$. time profile of phenytoin after administration of a single oral dose of 100 $\mathrm{mg}(3 \times 100$; a total of $300 \mathrm{mg})$ of phenytoin under fasting conditions. The pharmacokinetic parameters of phenytoin were estimated with softwares using Phoenix WinNonlin 6.4 or higher version and Microsoft Excel version 7.0. After logarithmic transformation, $\mathrm{AUC}_{(0-\infty)}, \mathrm{AUC}_{(0-\mathrm{t})}$ and $\mathrm{C}_{\max }$ values were subjected to analysis of variance (ANOVA), including the terms for subjects, treatment (sequence) and time period. The residuals of which were then tested for normality, as described by Chow \& Liu [32]. For the evaluation of bio-equivalence, the point estimates and $90 \%$ confidence interval (C.I.) for the relative difference between the test and reference formulations (test-reference) in each subject were constructed, using the residual mean 


\begin{tabular}{|c|c|c|c|c|}
\hline \multicolumn{5}{|c|}{$\begin{array}{c}\text { TABLE-3 } \\
\text { STABILITY SUMMARY OF PHENYTOIN }\end{array}$} \\
\hline Stability test & $\overline{Q C}$ & Mean \pm SD $\left(n g L^{1}\right)$ & Accuracy/stability (\%) & Precision $(\%)$ \\
\hline \multirow{2}{*}{$\begin{array}{l}\text { Auto sampler stability } \\
\quad(82 \mathrm{~h}, 30 \mathrm{~min})\end{array}$} & LQC & $330.3717 \pm 7.96866$ & 109.43 & 2.41 \\
\hline & HQC & $7737.4545 \pm 147.88627$ & 102.49 & 1.91 \\
\hline \multirow{2}{*}{$\begin{array}{l}\text { Wet extract stability } \\
\quad(78 \mathrm{~h}, 25 \mathrm{~min})\end{array}$} & LQC & $321.7963 \pm 7.60493$ & 106.59 & 2.36 \\
\hline & HQC & $7752.6005 \pm 152.51218$ & 102.69 & 1.97 \\
\hline \multirow{2}{*}{$\begin{array}{l}\text { Bench top stability } \\
\quad(6 \mathrm{~h}, 25 \mathrm{~min})\end{array}$} & LQC & $333.2090 \pm 9.52220$ & 110.37 & 2.86 \\
\hline & HQC & $7699.6332 \pm 110.94605$ & 101.99 & 1.44 \\
\hline \multirow{2}{*}{$\begin{array}{l}\text { Freeze-thaw stability } \\
\text { (four cycles) }\end{array}$} & LQC & $328.4350 \pm 4.55586$ & 108.79 & 1.39 \\
\hline & HQC & $7671.8922 \pm 81.56560$ & 101.62 & 1.06 \\
\hline \multirow{2}{*}{$\begin{array}{l}\text { Reinjection stability } \\
(0 \mathrm{~h})\end{array}$} & LQC & $315.5153 \pm 5.12792$ & 104.51 & 1.63 \\
\hline & HQC & $7498.0583 \pm 178.35924$ & 99.32 & 2.38 \\
\hline \multirow{2}{*}{$\begin{array}{c}\text { Short-term stability } \\
\text { (Freshly spiked QC's) }\end{array}$} & LQC & $334.0085 \pm 10.81075$ & 110.62 & 3.24 \\
\hline & HQC & $7704.4005 \pm 87.19068$ & 102.03 & 1.13 \\
\hline \multirow{2}{*}{$\begin{array}{c}\text { Short-term stability } \\
\left(\text { at }-20^{\circ} \mathrm{C} \text { for } 6 \text { days } 12 \mathrm{~h}\right)\end{array}$} & LQC & $325.5962 \pm 9.03039$ & 107.85 & 2.77 \\
\hline & HQC & $7757.6742 \pm 130.37950$ & 100.71 & 1.68 \\
\hline
\end{tabular}

TABLE-4

MEAN PHARMACOKINETIC PARAMETERS FOR PHENYTOIN, AFTER A SINGLE $100 \mathrm{mg}(3 \times 100$; A TOTAL OF $300 \mathrm{mg})$ ORAL DOSE ADMINISTRATION OF TEST AND REFERENCE FORMULATIONS TO SIXTEEN HEALTHY VOLUNTEERS

\begin{tabular}{ccc|cc}
\hline \multirow{2}{*}{ Parameter } & \multicolumn{2}{c|}{ Reference } & \multicolumn{2}{c}{ Test } \\
\cline { 2 - 5 } & Mean & Standard deviation & Mean & Standard deviation \\
\hline $\mathrm{C}_{\max }\left(\mathrm{ng} \mathrm{mL}^{-1}\right)$ & 4543.5099 & 642.76876 & 1847.5213 & 580.61684 \\
$\mathrm{~T}_{\max }(\mathrm{h})$ & 6.667 & 3.658 & 19.573 & 29.4726 \\
$\mathrm{~T}_{1 / 2}(\mathrm{~h})$ & 21.923 & 9.6836 & 220141.2557 & 6.4107 \\
$\mathrm{AUC}_{(0-\mathrm{t})}\left(\mathrm{ng} \mathrm{h} \mathrm{mL}^{-1}\right)$ & 207221.7164 & 50321.50881 & 215180.267 & 72272.70421 \\
$\mathrm{AUC}_{(0-\infty}\left(\mathrm{ng} \mathrm{h} \mathrm{mL}^{-1}\right)$ & 216178.6861 & 57786.4765 & 58213.42536 \\
$\mathrm{Kel}\left(1 . \mathrm{h}^{-1}\right)$ & 0.03681 & 0.014225 & 0.03929 & 0.013449 \\
\hline
\end{tabular}

TABLE-5

GEOMETRIC MEAN OF THE INDIVIDUAL AUC $(0-\mathrm{t}), \mathrm{AUC}_{(0-\infty)}$ and $\mathrm{C}_{\max }$ RATIOS (TEST/REFERENCE FORMULATION), THE RESPECTIVE $90 \%$ CONFIDENCE INTERVALS (CI) AND POWER

\begin{tabular}{|c|c|c|c|c|c|}
\hline \multirow{2}{*}{ Parameters } & \multirow{2}{*}{$\begin{array}{l}\text { Geometric mean } \\
\text { T/R ratio }(\%)\end{array}$} & \multicolumn{2}{|c|}{$90 \%$ Confidence interval } & \multirow{2}{*}{ Power } & \multirow{2}{*}{$\begin{array}{c}\text { Intra subject variability (relative } \\
\text { standard deviation } \% \text { ) }\end{array}$} \\
\hline & & Lower & Upper & & \\
\hline $\log C_{\max }\left(n g \mathrm{~mL}^{-1}\right)$ & 100.62 & 96.26 & 105.18 & 100 & 5.91 \\
\hline $\log \mathrm{AUC}_{0-\mathrm{t}}\left(\mathrm{ng} \mathrm{mL} \mathrm{m}^{-1}\right)$ & 103.72 & 97.46 & 110.38 & 99.96 & 8.31 \\
\hline
\end{tabular}

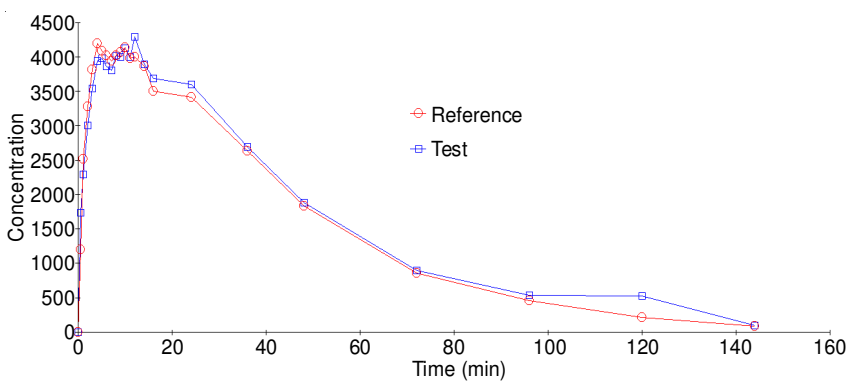

Fig. 4. Mean concentration time profile of phenytoin in human plasma after a single oral dose of $100 \mathrm{mg}(3 \times 100$; a total of $300 \mathrm{mg})$ administration of test and reference formulations to 16 healthy volunteers

square error obtained from the multi-factorial ANOVA. The bioequivalence between the two formulations was evaluated based on the $90 \%$ C.I. transformed back for the geometric mean ratios of $\mathrm{AUC}_{(0-\mathrm{t})}$ and $\mathrm{C}_{\max }$, which are recommended within the 80-125\% (Table-5) interval according to the USFDA and EMEA guidelines.

\section{Conclusion}

The LC-MS/MS assay reported here is simple, rapid, specific and sensitive for quantification of phenytoin in human plasma and is fully validated according to commonly acceptable FDA and EMEA guidelines. The simple solid-phase extraction method gave consistent and reproducible recoveries for the analyte from human plasma. This is the first LC-MS/MS report for the determination of phenytoin based on the SPE technique for sample preparation. The stability of the analyte in plasma and in aqueous samples under different conditions has been extensively evaluated. A sample turnover rate of less than 2 min makes it an attractive procedure in high-throughput bioanalysis of phenytoin. This method was found to be reliable and reproducible to support pharmacokinetic studies in humans (Table-4). The $90 \%$ confidence intervals were calculated for the $\mathrm{C}_{\max }, \mathrm{AUC}_{(0-\mathrm{t})}$ and AUC $_{(0-\infty)}$, giving values between $96.26-110.38 \%$ demonstrating the bioequivalence of the two formulations.

\section{REFERENCES}

1. D. Panomvana, N. Khummuenwai, S. Sra-lum and S. Towanabut, Curr. Ther. Res., 68, 325 (2007); https://doi.org/10.1016/j.curtheres.2007.10.007.

2. D. Blum, M. Reed and A. Metz, Prevalence of Major Affective Disorders and Manic/Hypomanic Symptoms in Persons with Epilepsy: A Community Survey, In: American Academy of Neurology, Denver, CO, USA (2002). 
3. A. Ettinger, M. Reed and J. Cramer, Neurology, 63, 1008 (2004); https://doi.org/10.1212/01.WNL.0000138430.11829.61.

4. M. Ha-Kaczyñska, Pharmacol. Rep., 59, ••(2007).

5. C. Temiz, P. Temiz, A. Demirel, M. Sayin, A.S. Umur and F.D. Özer, $J$ Clin. Neurosci., 16, 307 (2009); https://doi.org/10.1016/j.jocn.2007.12.007.

6. C.M. Ohnmacht, S. Chen, Z. Tong and D.S. Hage, J. Chromatogr. B Analyt. Technol. Biomed. Life Sci., 836, 83 (2006); https://doi.org/10.1016/j.jchromb.2006.03.043.

7. N.J. Gogtay, S.S. Dalvi, R.B. Mhatre, B.G. Kirodian, A.H. Gupta, S.P. Jadhav and N.A. Kshirsagar, Ther. Drug Monit., 25, 215 (2003); https://doi.org/10.1097/00007691-200304000-00012.

8. H. Kodama, Y. Kodama, S. Shinozawa, R. Kanemaru, K. Todaka and Y. Mitsuyama, J. Clin. Pharm. Ther., 23, 361 (1998); https://doi.org/10.1046/j.1365-2710.1998.00173.x.

9. M.C. Meyer, A.B. Straughn, R.M. Mhatre, V.P. Shah, M.-L. Chen, R.L. Williams and L.J. Lesko, Pharm. Res., 18, 394 (2001); https://doi.org/10.1023/A:1011075502215.

10. M.R. Nuwer, T.R. Browne, W.E. Dodson, F.E. Dreifuss, J. Engel, I.E. Leppik, R.H. Mattson, J. Penry, D.M. Treiman and B.J. Wilder, Neurology, 40, 1647 (1990); https://doi.org/10.1212/WNL.40.11.1647.

11. P.C. Lin, Y.H. Hsieh, F.F. Liao and S.H. Chen, Electrophoresis, 31 , 1572 (2010); https://doi.org/10.1002/elps.200900768.

12. E.J. Randinitis, R.A. Buchanan and A.W. Kinkel, Epilepsia, 31, 458 (1990); https://doi.org/10.1111/j.1528-1157.1990.tb05503.x.

13. M. Mikati, N. Bassett and S. Schachter, Epilepsia, 33, 359 (1992); https://doi.org/10.1111/j.1528-1157.1992.tb02328.x.

14. I. Soryal and A. Richens, J. Neurol. Neurosur. Psych., 55, 688 (1992); https://doi.org/10.1136/jnnp.55.8.688.

15. G.L. Lensmeyer, B.E. Gidal and D.A. Wiebe, Ther. Drug Monit., 19, 292 (1997); https://doi.org/10.1097/00007691-199706000-00009.

16. M.M. Bhatti, G.D. Hanson and L. Schultz, J. Pharm. Biomed. Anal., 16, 1233 (1998); https://doi.org/10.1016/S0731-7085(97)00265-3.

17. K.M. Patil and S.L. Bodhankar, J. Pharm. Biomed. Anal., 39, 181 (2005); https://doi.org/10.1016/j.jpba.2005.02.045.

18. R.H.C. Queiroz, C. Bertucci, W.R. Malfará, S.A.C. Dreossi, A.R. Chaves, D.A.R. Valério and M.E.C. Queiroz, J. Pharm. Biomed. Anal., 48, 428 (2008);

https://doi.org/10.1016/j.jpba.2008.03.020.
19. T.A.C. Vermeij and P.M. Edelbroek, J. Chromatogr. B Analyt. Technol. Biomed. Life Sci., 857, 40 (2007); https://doi.org/10.1016/j.jchromb.2007.06.023.

20. M.J. Cwik, M. Liang, K. Deyo, C. Andrews and J. Fischer, J. Chromatogr. B Biomed. Sci. Appl., 693, 407 (1997); https://doi.org/10.1016/S0378-4347(97)00057-1.

21. Q. Fenghe, L. Li, L. Yi and L. Yongquan, Se Pu, 13, 218 (1995).

22. S. Bardin, J.C. Ottinger, A.P. Breau and T.J. O'Shea, J. Pharm. Biomed. Anal., 23, 573 (2000); https://doi.org/10.1016/S0731-7085(00)00338-1.

23. S.M.N. Roy, S.M. Yetal, V.V. Vaidya and S.S. Joshi, E-J. Chem., 5, 169 (2008); https://doi.org/10.1155/2008/362512.

24. Y. Zhang, N. Mehrotra, N.R. Budha, M.L. Christensen and B. Meibohm, Clin. Chim. Acta, 398, 105 (2008); https://doi.org/10.1016/j.cca.2008.08.023.

25. S.L. Dalmora, D.R. Nogueira, L.F. Londero, D.P. Santana and T.M. Goncalves, Lat. Am. J. Pharm., 28, 247 (2009).

26. M. Achim, D. Muntean, L. Vlase, I. Baldea, D. Mihu and S.E. Leucuta, Stud. Univ. Babes-Bolyai Chem., 54, 7 (2009).

27. D. Wang, X.Y. Chen and Y.F. Zhang, Zhongguo Lin Chuang Yao Li Xue Za Zhi, 22, 213 (2006).

28. A. Zarghi, K. Gholami and M. Hessami, Boll. Chim. Farm., 138, 508 (1999).

29. FDA, Center for Drug Evaluation and Research, US Department of Health and Human Services, Guidance for Industry, Bioanalytical Method Validation (2001).

30. FDA, Center for Drug Evaluation and Research, US Department of Health and Human Services, Guidance for Industry, Bioavailability and Bioequivalence Studies for Orally Administered Drug Products-General Considerations (2002).

31. B.K. Matuszewski, J. Chromatogr. B Analyt. Technol. Biomed. Life Sci., 830, 293 (2006); https://doi.org/10.1016/j.jchromb.2005.11.009.

32. S.C. Chow and J.P. Liu, Design and Analysis of Bioavailability and Bioequivalence Studies, Marcel Dekker, New York, edn 2 (2000). 